\title{
Mutual Olfactory RECOGNITION BETWEEN MOTHER AND CHILD
}

\section{S. Craig Roberts \& Faize Eryaman}

Division of Psychology, University of Stirling, Stirling, United Kingdom

\section{craig.roberts@stir.ac.uk}

\begin{abstract}
The ability of infants to recognize their mother is an important factor in the development of mother-infant social relationships. Infants must be able to distinguish her from other individuals before they form strong maternal attachment, and learning individual characteristics of the child likely helps to cement the mother's emotional bonding with the child. Existing evidence demonstrates that very young infants can discriminate their mother's odour and that this facilitates the onset and duration of breastfeeding, but it is not known whether this ability is maintained after weaning. Here, we investigated recognition of mothers by children of toddler age ( 3 - 5 years), and maternal recognition of her child, through body odour. Nineteen mother-child pairs wore clean t-shirts for 2 consecutive nights, and both mothers and children were then tested for correct identification of their respective mother/ child's odour from an odour line-up of 6 samples. We found that mothers were able to recognise their child's odour at rates above chance, but toddlers were not. Neither breastfeeding duration nor hours spent together on an average day were associated with correct odour recognition by either mothers or children. However, higher perceived pleasantness of their child's odour during testing was associated with higher identification success, suggesting a possible cue to correct identification in mothers. Mothers who correctly identified their child's odour were also more likely to correctly identify the sex of odour donors. Our study contributes to the growing literature suggesting that odour may be important in maternal-child attachment.
\end{abstract}

Keywords: Olfaction, smell, olfactory communication, bonding. 


\section{INTRODUCTION}

Individual recognition is a prerequisite for the formation of any kind of social attachment. In order to have a bond with another individual, that person must be individually distinct from others (Porter and Winberg, 1999). For example, the ability of infants and mothers to recognize each other has a significant role in the development of mother-infant social relationships and attachment (Bowlby, 1969; Schaffer, 1971); failure of such attachment may explain sub-optimal social bonding and maturation in children who are separated from their mother shortly after birth, even after being reunited with their natural parents (Bowlby, 1975; Klaus et al., 1970). There is agreement that primary social experiences may have comprehensive lasting developmental and physiological effects for mothers and infants (Klaus et al., 1970; Bystrova et al., 2009; Als et al., 2004). Mother-infant communications through infancy support the development of emotional attachments, language procurement and social understanding, as well as cognitive faculties, biological organization and endure to diseases (Macfarlane, 1975). For the human infant, recognising and being recognised by his/ her mother, locating and latching onto the breast are undoubtedly evolutionarily significant survival abilities (Hugill, 2015), and infants must be able to discriminate between their own mother and other individuals (Cernoch and Porter, 1985).

In many mammalian species, offspring depend on olfactory cues to aid the recognition of the mother's nipple and to encourage feeding (Porter, Fullerton and Berryman, 1973; Schaal et al., 2009). Similarly, a growing literature indicates that chemical signals might play an important role in human maternal-infant bonding and communication. Very young infants can identify their mothers using smell (Macfarlane, 1975; Varendi and Porter, 2001). For example, Schaal et al. (1980) showed that infants orientate towards parts of clothes that have had contact with the axillae and worn by their own mothers compared to clothes worn by other mothers. However, most research attention has focused on infants' interest in mother's breast odour. Macfarlane (1975) used head-turning towards one of two breast pads as an indication of preference in newborns. In one experiment, 5-day old infants turned towards a pad that had been in contact with the mother's breast for 3-4 hours more than towards a control, odourless pad; in a second experiment, 6-day old infants turned more towards a pad that had been in contact with the child's mother's breast compared with another that had had contact with the breast of another mother. Newborn babies also orient preferentially towards breast odours of lactating over those of non-lactating women (Makin \& Porter 1989).

The ability to learn maternal odours appears to be related to the act of breast-feeding: infants who are being breast-fed demonstrate preference for maternal odours but these are not evident in bottle-fed infants (Cernoch \& Porter 1985). Such a pattern suggests that these responses are learned and conditional, rather than instinctive responses, as suggested by Porter et al. (1991). Such learning appears to begin with the neonate's first attempt to locate the nipple, focusing on the odour cues on the breast that release activity in newborns, such as secretions from the areolar glands (Doucet et al., 2007; Schaal et al., 2006).

Mothers may also learn their baby's odour. Newborns' odour cues are salient to their mothers and mothers are able to discriminate their own newborn baby's odour from another newborn baby (Schaal et al., 1980). Recognition of infant's odour by mothers, 
using clothing worn by the infant, can be shown even within the first week of birth (Fleming et al., 1995) or even the first 2 days (Porter, Cernoch and McLaughlin, 1983). In another study, Russell et al. (1983) tested mothers at either 6 hours or 48 hours postpartum - success raters were significantly better than chance at 6 hours, and occurred at the same rate (i.e. had not markedly improved with further learning) after $48 \mathrm{~h}$. Furthermore, Weisfeld et al. (2003) show that mothers can reliably recognise the odours of their preadolescent biological children, but not adopted children.

In comparison to this research on young infants, relatively few studies have examined whether these odour preferences persist in older children. According to Schaal et al. (1980), one-third of 3 to 5 year old children preferred a $t$-shirt worn for a few days by their own mother over other $\mathrm{t}$-shirts worn by an unfamiliar mother or shirts without a specific odour. However, Ferdenzi et al. (2010) found that children aged 7-10 performed at rates no different from chance when asked to identify their mother's odour, although mothers could still recognise these children. Arguably, the adaptive benefits to be gained from this recognition should decrease with age in children, and indeed at some point it will become much more important to be able to focus on opposite-sex individuals of the same age as children approach puberty (Ferdenzi et al., 2010).

In the present study, we set out to replicate Schaal et al.s (1980) study by testing children's ability to recognize their mothers at 3-5 years of age, and to test the success with which mothers can recognize their own child at this age. In addition, we explored the possibility that moderating effects such as breastfeeding duration or time spent together on an average day might predict this mutual olfactory recognition.

\section{METHOD}

\section{Participants}

The sample consisted of nineteen mothers and child pairs. Children were aged between 3 and 5 years old (mean $=3.74$ years). Eleven of the children were male and 8 were female. Seventeen mother-child pairs were recruited from our university's Division of Psychology Playgroup, and the other two pairs from nearby nurseries. All the participants were healthy, physically able and there was no sign of developmental delay in any of the children.

Parents were informed about the study before the data collection and informed consent was collected. There was no compensation for taking part for the mothers, but children were offered stickers for participation. All mothers and children were tested at the University of Stirling Playgroup test facility.

The study was approved by the Committee on Research Ethics of the University of Stirling.

\section{Odour Sample Collection}

Participating mothers were given a recruitment pack containing the necessary materials. Each pack for mothers was a zip-lock plastic bag that contained an instruction sheet about how to collect body odours (for themselves and their children), a $100 \%$ cotton $t$ shirt and a block of non-perfumed soap. Mothers also received a pack for their children 
with a $100 \%$ cotton, child-sized t-shirt. Both shirts had been washed with an unscented detergent. Following previous odour studies (e.g. Roberts et al., 2008), mothers and children were asked to wear the t-shirts for 2 consecutive nights and bring them back to the nursery on the morning of the third day. As is typical in human odour studies, we asked participants to refrain from eating strong foods (e.g., chilli and other spices, curry, garlic, pepperoni, onion, asparagus, vinegar, cabbage, blue cheese; see Roberts et al., $2005,2008)$. On the evening that odour collection started, before putting the $t$-shirts on, all mothers and children were required to shower with a non-perfumed soap (Simple ${ }^{\mathrm{TM}}$ ) that was provided by the researchers, and were instructed not to use any scented products such as deodorants, colognes, antiperspirants, shower gels, perfumed soaps, or perfumes. Mothers were asked to avoid sexual intercourse or sleeping in the same bed with their partner during the two nights and odour contamination (from another child, partner, cooking, pets or other odorous clothes) during the time they wore the t-shirt. No odour contamination (by tobacco, coffee, or perfume, for example) was recorded by one researcher (FE) who smelled every $t$-shirt once. On the morning of each collection night, participants were asked to store their t-shirt in the closed and identified zip-lock bag provided.

On return to the nursery, sealed bags containing the $t$-shirts were put into the freezer within 2 hours and stored there for a maximum length of 32 days. Previous studies have shown that freezing length over this time frame does not influence body odour quality (Roberts et al., 2008; Lenochova et al., 2009).

\section{Evaluation Procedure}

Each mother and child were tested together, in a room in the playgroup facility. We presented them with six odours each. For mothers, they were presented with the t-shirt worn by their own child and shirts worn by 5 other children; children were presented with their own mother's shirt and those worn by 5 other mothers. To our knowledge, mothers and children were not closely familiar with other children or mothers whose odours they were presented with. The other 5 shirts were chosen at random from the other 18 available (using the Rand function in Excel). Sets of shirts were presented in clear glass jars with a code on the base for the experimenter's use.

Mothers were asked to smell every t-shirt and rate the odour of each shirt using a 7 point Likert scale, for odour pleasantness $(1=$ not pleasant at all, $7=$ very pleasant $)$ and odour intensity ( $1=$ not intense at all, $7=$ very intense). They were also asked to guess the sex of the child (boy/girl), and to guess which odour of the 6 odours belonged to their own child. They were told that they could smell any of the jars as often as they wished. In addition, they were asked to answer the questions "for about how many weeks did you breastfeed the child who wore the shirt?" and "How many hours do you spend with your child on an average day in the past week?".

Children were presented with 6 shirts in jars (one from their mother and 5 from other mothers). They were shown how to smell each jar properly, by the experimenter, and special care was given to ensure that they understand how to do it and the question that was posed. In contrast to mothers, children were given only a single task: they were asked to smell the jars and identify "which one smells like your mummy?". After the test 
session, every child received a sticker from the experimenter. Each test session lasted for approximately 10 minutes.

\section{Statistical Analysis}

Data were analysed using SPSS Statistics version 23. We used binomial tests to compare the frequency of correct identifications against chance ( 1 of 6 , i.e. 0.167$)$. One-tailed tests were used because a specific prediction was made that mothers will be able to do this at rates above chance or not at all, but not that they would be significantly worse than chance. As sample sizes were relatively small, and data on breastfeeding and time spent together were not normally distributed, we used non-parametric techniques for other tests. We compared breastfeeding duration and time spent together on an average day, between mothers who correctly and incorrectly identified their own child, using two-sample Kolmogorov-Smirnov tests. For tests of the association between the same groups of mothers and their ability to accurately identify sex of the odour donors, we used Kendall's tau-b tests.

\section{RESULTS}

\section{Mutual Odour Recognition in Children and Mothers}

Among the children, 6 of 19 (31.6\%) correctly identified their mother's odour, which was close to but not significantly higher than chance levels (binomial test: $p=0.083$ ). However, 7 of 19 mothers $(36.8 \%)$ correctly identified their child's odour, which was higher than the chance expectation of 0.167 (binomial test: $p=0.028$, Fig. 1 ).

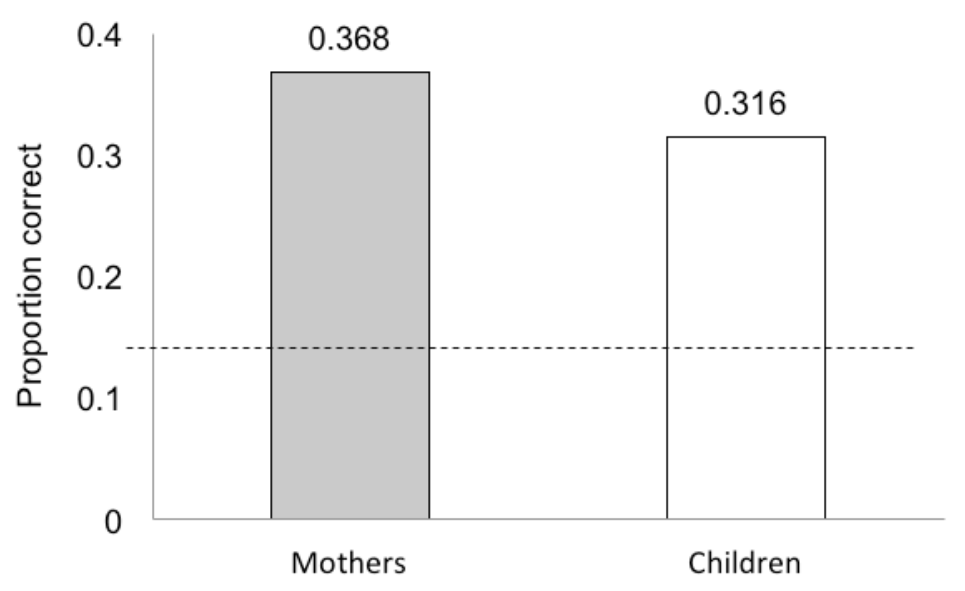

Figure 1. Observed proportions of mothers who correctly identified their child and of children who correctly identified their mother. Dotted line indicates the chance proportion (0.167). 


\section{Predictors of children's recognition of their mother}

We tested whether children who guessed their mother correctly were breastfed longer than others who guessed incorrectly, or spent more hours together on an average day than others. There was no difference $(z=0.312, p=0.323)$ in breastfeeding duration across correct or incorrect guessers, although (contrary to expectation) children who recognized their mother were breastfed for a shorter period - an average of $20.33 \pm 8.89$ weeks - compared to $45.12 \pm 12.68$ weeks for children who guessed incorrectly. There was also no difference $(z=0.416, p=0.99)$ in time spent with mothers on an average day (correct: $11.33 \pm 2.47$ hours; incorrect: $10.46 \pm 1.47$ hours). Thus, neither measure of physical contact was a predictor of correct identification of the mother's odour.

\section{Predictors of mother's recognition of their child}

Similarly, we compared the number of hours spent together on an average day and duration of breastfeeding between groups of mothers who correctly or incorrectly identified their child's odour. Again, there was no significant difference in time spent with their child between correct and incorrect guessers $(z=0.53, p=0.945$; correct mean \pm s.e.: $9.57 \pm 1.51$, incorrect: $11.42 \pm 1.77)$, nor in duration of breastfeeding $(z=$ $0.71, p=0.709 ; 24.9 \pm 10.3$ weeks compared with $44.6 \pm 13.4$ for correct and incorrect guessers, respectively).

We then tested whether there was a difference in perceived pleasantness of their child's odour. We subtracted the pleasantness score that mothers assigned to their child's odour (note that mothers did not know for sure that the odour did belong to their child when they scored them) from the average of the other 5 assessed odours. We found that this difference score for odour pleasantness was higher $(z=1.40, p=0.039$; Fig.2) in mothers who correctly identified their child, while there was no difference in rated odour intensity $(z=0.80, p=0.543$ ), indicating that they may have used pleasantness as a subconscious cue to their identification decision.

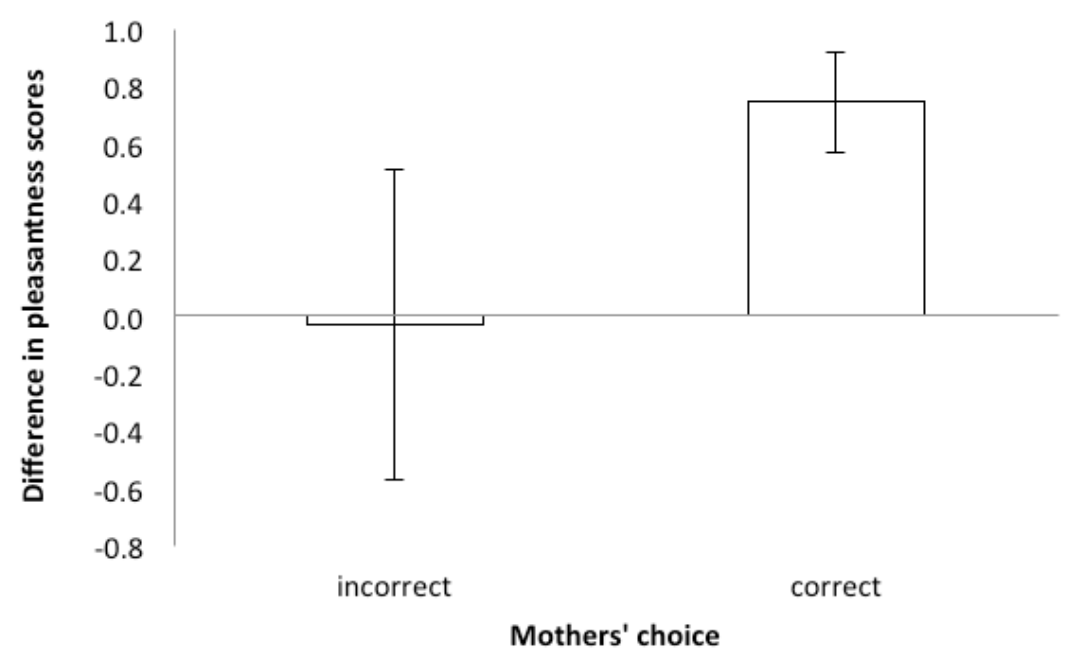

Figure 2: Mean ( \pm s.e.) difference in perceived pleasantness of their own child's odour and those of the other 5 children's odours, in mothers who correctly or incorrectly identified their own child's odour. Larger positive differences indicate a relative preference for their own child's odour. 
Finally, we compared mothers' success in an associated olfactory task while they assessed the shirts: their accuracy in correctly guessing the sex of the odour donor. We found that mothers who correctly identified their child's odour were also more likely to correctly indicate the sex of the odour donor when they assessed their own child's odour (i.e. perceived their own child's sex to be correct, even though they could not be sure it was their child's odour). Of the 7 who identified their child correctly, 6 guessed the sex of the odour donor correctly, while of the 12 who incorrectly identified their child, only 5 indicated the correct sex when smelling that odour (Kendall's tau-b, $T=2.18, p=0.029$ ). Furthermore, those who accurately identified their child's odour also correctly identified the sex of a higher number of the other five odours. We tested this by categorising mothers into those who accurately guessed the sex of 3 or more of the other 5 odours ("good smellers", $n=11$ ) and those who accurately guessed the sex of 2 or fewer of the other 5 odours ("poor smellers, $n=8$ ). 'Good smellers' were more likely to correctly identify their own child's odour ( $T=2.89, p=0.004$; Fig.3).

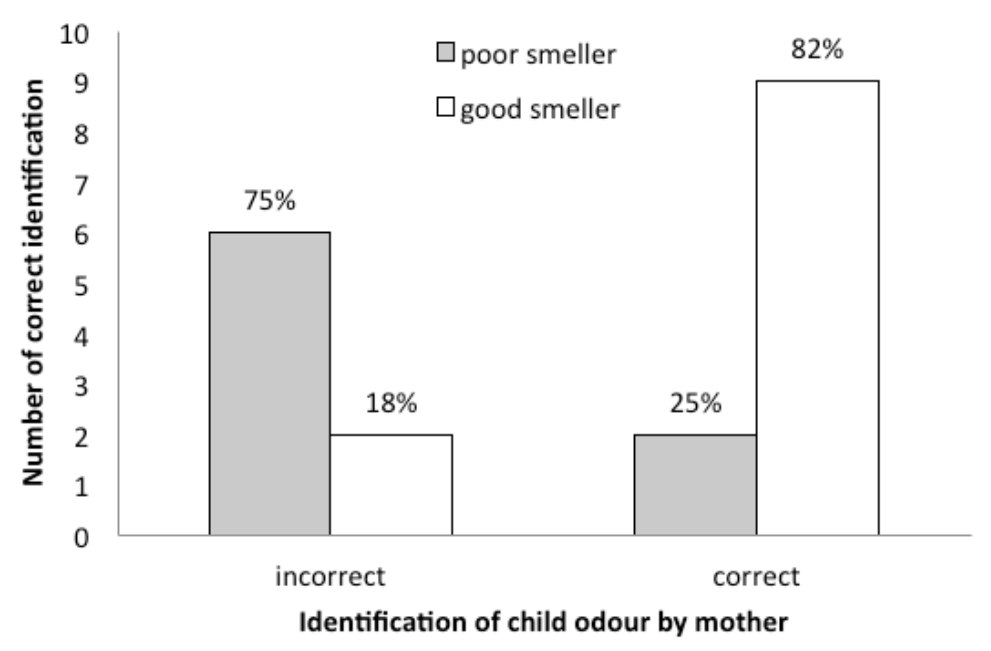

Figure 3. The number of mothers who correctly or incorrectly identified their child's odour according to their ability to correctly recognise the sex of the other 5 children's odours ("poor smellers" were correct in 2 or fewer guesses, "good smellers" were correct in 3 or more guesses).

\section{DISCUSSION}

The main aim of this study was to determine whether mutual olfactory recognition is maintained in older children, beyond infanthood. We tested this in children aged between 3 and 5 years old. We found that children did not recognise their mothers at rates above chance, with only 6 of 19 children achieving the correct result. It should be noted, however, that just one additional correct response would have returned a statistically significant result, so the result should be treated with some caution. By the same token, although 7 of 19 mothers were successful in recognizing their own child, which was statistically greater than chance, just one fewer mother being successful would have resulted in a non-significant effect, so this too should be treated with caution. 
Nonetheless, our results are in accord with those of Ferdenzi et al. (2010), who found that slightly older children failed to recognise their mothers's odours even though mothers could still recognise the odours of these older children.

There is significant individual variation in human body odour (e.g. Havlíček et al., 2017), and previous studies on maternal recognition have shown that mothers can discriminate their newborn baby's body odour from that of other babies (Schaal et al., 1980; Fleming et al., 1995; Porter et al., 1983; Russell et al., 1983). However, there is a relative paucity of studies testing whether mothers can continue to recognise their child beyond infanthood. Our findings suggest that mothers continue to identify their offspring's odour at rates better than chance at least until children are between 3 and 5 years of age, consistent with two previous studies (Ferdenzi et al., 2010; Weisfeld et al., 2003).

Interestingly, our results also indicated that breastfeeding duration and hours spent together on an average day does not have an effect on the success in identifying one's mother or child. However, there was some indication that the main constraint on rates of successful identification may be related to underlying olfactory ability more generally. Those mothers who more often guessed the other donors' sex correctly were more likely to also recognise their own child's odour, and mothers who correctly identified their child were also significantly more likely to have guessed correctly the sex of the child they smelled when assessing their own child's odour (not knowing which was theirs). Our data also indicate a correlation between recognition and odour pleasantness. Mothers who correctly identified their child's odour also found, on average, their own child's odour to be more pleasant than those of the other presented odours. They were not aware when they rated the odour pleasantness which odour was in fact their child's, so this association suggests a plausible subconscious mechanism which may help in identification. Previous studies have demonstrated links between familiarity and pleasantness of odours (e.g. Distel et al. 1999; Ferdenzi et al., 2013), which may underpin this relationship, especially as correlations between familiarity and odour pleasantness are stronger for pleasant than unpleasant odours (Delplanque et al., 2008).

As for children, they failed to identify their mothers' body odour at rates above chance. If we interpret the results at face value, it may be that recognition of mother's smells in infanthood is possible because her odour is more distinctive around the perinatal period. According to Vaglio (2009), mothers develop a distinctive pattern of 5 volatile compounds common to the nipple-areola and para-axillary regions in late pregnancy and early post-partum, and perhaps these odour changes shape their distinctiveness. In addition, it is possible that the benefits of recognition are simply more important when at this time, since babies must find the breast for nourishment, compared to post-weaning, and perhaps because they rely more on olfaction than vision at this time of their development. Another reason why toddlers may not continue to be able to recognize their mothers is that mothers are more likely to have resumed use of perfumes compared to when they were breastfeeding, and perfumes not only carry their own fragrance but also produce unique odour mixtures when blended with body odour (Lenochová et al., 2012). Since we asked mothers to refrain from perfume use during odour collection, this would introduce a discrepancy between the odour to which toddlers have become accustomed and the stimuli presented. Such a discrepancy would, 
of course, not be a factor for mothers assessing their toddler, since few toddlers wear perfumes.

On the other hand, the lower correct identification rate amongst children could be attributed to a difference in the relative difficulty in the task for mothers and children. First, it is likely that the cognitive load of remembering and comparing six odours is relatively harder for young children compared to adults. Second, it is possible that the task itself was harder for children, in that they compared among six adult females while mothers compared a mixture of young boys and girls. Thus, homogeneity among odours arising from sex differences may have been lower among those assessed by mothers than those assessed by children. In light of this, further studies might consider alternative designs using forced choice tests between pairs of odours and where odours within a pair are always from donors of the same sex.

In conclusion, our study showed that mothers continue to recognize their child's odour beyond infanthood. Toddlers appear to do less well than both mothers and younger children, although this requires further testing with an alternative design before firm conclusions may be drawn. However, at least for mothers, our results suggest that the benefits of maternal recognition for infants are adaptive and continue for at least several years beyond weaning.

\section{ACKNOWLEDGEMENTS}

We are grateful to two anonymous reviewers for their helpful comments on an earlier version of this manuscript.

\section{REFERENCES}

Als, H., Duffy, F. H., McAnulty, G. B., Rivkin, M. J., Vajapeyam, S., Mulkern, R. V., Warfield, S. K., Huppi, P. S., Conneman, N., Fischer C., \& Eichenwald, E. C. (2004). Early experience alters brain function and structure. Pediatrics, 113, 846-857. DOI

Bowlby, J. (1969). Attachment and loss: Vol.1. Attachment. New York: Basic Books.

Bowlby, J. (1973). Attachment and loss: Vol. 2. Separation: Anxiety and anger. New York: Basic Books.

Bystrova, K., Ivanova, V., Edhborg, M., Matthiesen, A., Ransjö-Arvidson, A., Mukhamedrakhimov, R., Uvnäs-Moberg, K., \& Widström, A. (2009). Early contact versus separation: effects on mother-infant interaction one year later. Birth, 36, 97-109. $\underline{\text { DOI }}$

Cernoch, J. \& Porter, R. (1985). Recognition of maternal axillary odors by infants. Child Development, 56, 1593-1598. DOI

Delplanque S., Grandjean D., Chrea C., Aymard L., Cayeux I., Le Calvé B., Velazco, M. I., Scherer, K.R., Sander, D. (2008). Emotional processing of odours: evidence for a non-linear relation between pleasantness and familiarity evaluations. Chemical Senses, 33, 469-479. $\underline{\mathrm{DOI}}$ 

Human Ethology Bulletin 32 (2017)1- Proc. of the XXIII Biennial ISHE Congress: $42-52$

Distel H., Ayabe-Kanamura S., Martinez-Gomez, M., Schicker I., Kobayakawa T., Saito S., Hudson, R. (1999). Perception of everyday odors-correlation between intensity, familiarity and strength of hedonic judgement. Chemical Senses, 24, 191-199. DOI

Doucet, S., Soussignan, R., Sagot, P., \& Schaal, B. (2007). The "smellscape" of mother's breast: Effects of odor masking and selective unmasking on neonatal arousal, oral, and visual responses. Developmental Psychobiology, 49, 129-138. DOI

Ferdenzi C., Roberts S. C., Schirmer A., Delplanque S., Cekic S., Porcherot C., Cayeux, I., Sander, D., Grandjean, D. (2013). Variability of affective responses to odors: culture, gender and olfactory knowledge. Chemical Senses, 38, 175-186. DOI

Ferdenzi, C., Schaal, B., \& Roberts, S.C. (2010). Family scents: developmental changes in body odor perception of kin. Journal of Chemical Ecology, 36, 847-854. DOI

Fleming, A., Corter, C., Surbey, M., Franks, P., \& Steiner, M. (1995). Postpartum factors related to mother's recognition of newborn infant odours. Journal of Reproductive and Infant Psychology, 13, 197-210. DOI

Havlíček, J., Fialová, J. \& Roberts, S. C. (2017). Individual variation in body odor. In Buettner, A., (ed.) Handbook of Odor, pp. 949-961. Springer. DOI

Hugill, K. (2015). The senses of touch and olfaction in early mother-infant interaction. British Journal of Midwifery, 23, 238-243. DOI

Klaus, M. H., Kennell, J. H., Plumb, N., \& Zuehlke, S. (1970). Human maternal behavior at the first contact with her young. Paediatrics, 46, 187-192.

Lenochova, P., Roberts, S.C., \& Havlicek, J. (2009). Methods of human body odor sampling: the effect of freezing. Chemical Senses 34, 127-138. DOI

Lenochová P, Vohnoutová P, Roberts SC, Oberzaucher E, Grammer K, \& Havlíček J. (2012). Psychology of fragrance use: perception of individual odor and perfume blends reveals a mechanism for idiosyncratic effects on fragrance choice. PLoS One e33810. DOI

Macfarlane, A. (1975) Olfaction in the development of social preferences in the human neonate. In R. Porter \& M. O'Connor (eds) Ciba Foundation Symposium 33 - Parent-Infant Interaction, pp. 103-113. John Wiley \& Sons, Ltd., Chichester, UK. DOI

Makin, J. W., Porter, R. H. (1989). Attractiveness of lactating females' breast odors to neonates. Child Development, 60, 803-810. DOI

Porter, R. H., Berryman, J. C. \& Fullerton, C. (1973). Exploration and attachment behaviour in infant guinea pigs. Behaviour 45, 312-322. DOI

Porter, R., Cernoch, J., \& McLaughlin, F. (1983). Maternal recognition of neonates through olfactory cues. Physiology \& Behavior, 30, 151-154. DOI

Porter, R. H., Makin, J. W., Davis, L. B., \& Christensen, K. M. (1991). An assessment of the salient olfactory environment of formula-fed infants. Physiology \& Behavior, 50, 907-911. $\underline{\mathrm{DOI}}$

Porter, R. \& Winberg, J. (1999). Unique salience of maternal breast odors for newborn infants. Neuroscience \& Biobehavioral Reviews, 23, 439-449. DOI

Roberts, S. C., Gosling, L. M., Carter, V., \& Petrie, M. (2008). MHC-correlated odour preferences in humans and the use of oral contraceptives. Proceedings of the Royal Society B: Biological Sciences, 275, 2715-2722. DOI 
Roberts, S. C., Gosling, L. M., Spector, T. D., Miller, P., Penn, D. J., \& Petrie, M. (2005). Body odor similarity in noncohabiting twins. Chemical Senses, 30, 651-656. DOI

Russell, M. J., Mendelson, T., \& Peeke, H. (1983). Mother's identification of their infant's odors. Ethology and Sociobiology, 4, 29-31. DOI

Schaal, B., Coureaud, G., Doucet, S., Delaunay-El Allam, M., Moncomble, A., Montigny, D., Patris B. \& Holley, A. (2009). Mammary olfactory signalisation in females and odor processing in neonates: Ways evolved by rabbits and humans. Behavioral Brain Research, 200, 346-358. DOI

Schaal, B., Doucet, S., Sagot, P., Hertling, E., \& Soussignan, R. (2006) Human breast areolae as scent organs: morphological data and possible involvement in maternal-neonatal coadaptation. Developmental Psychobiology 48, 100-110. DOI

Schaal, B., Montagner, H., Hertling, E., Bolzoni, D., Moyse, A., \& Quichon, R. (1980). Les stimulations olfactives dans les relations entre l'enfant et la mère. Reprod. Nutr. Dévelop., 20(3B), 843-858. DOI

Schaffer, H. R. (1971). The growth of sociability. Harmondsworth, Middlesex: Penguin.

Vaglio, S., Minicozzi, P., Bonometti, E., Mello, G., \& Chiarelli, B. (2009). Volatile signals during pregnancy: a possible chemical basis for mother-infant recognition. Journal of Chemical Ecology, 35, 131-139. DOI

Varendi, H. \& Porter, R. (2001). Breast odour as the only maternal stimulus elicits crawling towards the odour source. Acta Paediatrica, 90, 372-375. DOI

Weisfeld, G. E., Czilli, T., Phillips, K. A., Gall, J. A., Lichtman, C. M. (2003). Possible olfactionbased mechanisms in human kin recognition and inbreeding avoidance. J. Exp. Child Psychol. 85:279-295. DOI 